\title{
Evaluation of Enhancement Factor for Removal of Heavy Metal Ions from Water through Adsorption by Non-Activated and Activated Carbon Prepared from Rice Husk
}

\author{
Muhammad Irfan ${ }^{a *}$, Amir Shafeeq ${ }^{b}$, Tahir Saleem Nasir ${ }^{b}$, Farzana Bashir ${ }^{a}$, Tausif Ahmad \\ Naeem Abbas ${ }^{a}$, Muhammad Tahir Butt ${ }^{\mathrm{a}}$ and Farah Deeba ${ }^{\mathrm{a}}$ \\ ${ }^{a}$ Centre for Environmental Protection Studies, Pakistan Council of Scientific and Industrial Research (PCSIR) \\ Laboratories Complex, Ferozpur Road, Lahore, Pakistan \\ ${ }^{b}$ Institute of Chemical Engineering \& Technology, University of the Punjab, Lahore - 54590, Pakistan \\ ${ }^{\mathrm{c} C h e m i c a l ~ E n g i n e e r i n g ~ D e p a r t m e n t, ~ U n i v e r s i t i ~ T e k n o l o g i ~ P E T R O N A S, ~ B a n d a r ~ S e r i ~ I s k a n d a r, ~ 32610, ~}$ \\ Perak, Malaysia
}

(received January 15, 2020; revised October 28, 2020; accepted November 11, 2020)

\begin{abstract}
Removal of heavy metal ions (HMI) from water streams is desirable due to their toxic and carcinogenic effects. Therefore, this study was conducted to prepare a low cost adsorbent in the form of non-activated carbon (NAC) and activated carbon (AC) using rice husk, a local bio-waste material. Activation of material was performed by base leaching, chemical activation using $\mathrm{ZnCl}_{2}$, followed by acid washing. The initial and final concentrations of HMI in water were measured using Atomic Absorption Spectroscopy. Volatile matter, ash, moisture and surface area of the prepared material were measured using ASTM methods E 897- 88 R04, E 830 - 87 R04, E 949 - 88 R04 and D 1050 - 1 respectively. An enhancement factor was used to evaluate the activating effect of the adsorbent. Maximum \% age removal of HMI was measured as 69.0, 64.0, 62.0 and $56 \%$ for $\mathrm{Ni}, \mathrm{Cd}, \mathrm{Zn}$ and $\mathrm{Pb}$ respectively using NAC. However, by using AC, a significant increase in the \%age removal efficiency of HMI was observed and measured as 99.0, 95.5, 93.0 and $89 \%$ for $\mathrm{Ni}, \mathrm{Cd}, \mathrm{Zn}$ and $\mathrm{Pb}$ respectively. The results showed that $\mathrm{AC}$ derived from waste biomass is a simple, ecological and cost-effective approach to remove bulk of metal ions from water and wastewater.
\end{abstract}

Keywords: heavy metal ions, water, adsorption, activated carbon, zinc chloride, rice husk

\section{Introduction}

Metals with a density of more than $5 \mathrm{~g} / \mathrm{cm}^{3}$ are classified as heavy metals. Many elements fall within this range; however some are of greater environmental concern and are listed in Table 1 (Barakat, 2011). The concentration of heavy metal ions (HMI) in effluents has increased rapidly in recent years with the rapid growth of industries (Masindi and Muedi, 2018). Heavy metals may include cadmium $(\mathrm{Cd})$, copper $(\mathrm{Cu})$, mercury $(\mathrm{Hg})$, chromium $(\mathrm{Cr})$, lead $(\mathrm{Pb})$, iron $(\mathrm{Fe})$, nickel $(\mathrm{Ni})$ and zinc ( $\mathrm{Zn})$ etc. These metals are potentially unsafe and have harmful effects on human physiology and biological systems, particularly when their concentrations increase from an acceptable safe level $(\mathrm{Fu}$ and $\mathrm{Xi}$, 2020). Therefore, modern research is much inclined toward removal of HMI from water streams using those methods which are economically attractive, simple to use and eco-friendly in nature. Numerous techniques have been used to remove the solid particulates from

*Author for correspondence; E-mail: sahalirfan@gmail.com the wastewater, including precipitation, membrane filtration, ion-exchange and adsorption (Malik et al., 2019). Chemical precipitation has been widely employed to remove contaminants which are inorganic in nature. This approach uses different chemical agents such as lime or lime water to precipitated HMI from solution. The advantages of chemical precipitation technique are the easy availability of materials and equipment, as well as simple process conditions. However, too much quantity of sludge production, high quantity of precipitators, time consuming process, high cost and environmental concerns of sludge disposing are the main constraints (Barakat, 2011). Membrane filtration can be used to cope with the bulk amount of precipitators and sludge volume. However, low filtration rates coupled with high capital and maintenance cost are the key barriers to limit the scope of this method. Ion exchange method is another technique used for HMI removal from wastewater. In this approach, synthetic resins are used as ion exchangers, which are responsible for regeneration of metal ions (Bashir et al., 2019). 
Table 1. Maximum contaminant level (MCL) standards for the few hazardous heavy metals (Barakat, 2011).

\begin{tabular}{lll}
\hline \hline Heavy metal & Toxicities & MCL(mg/L) \\
\hline $\mathrm{Zn}$ & Depression, lethargy, neurological signs and increased thirst & 0.80 \\
$\mathrm{Copper}$ & Liver damage, Wilson disease, insomnia & 0.25 \\
$\mathrm{Ni}$ & Dermatitis, nausea, chronic asthma, coughing, human carcinogen & 0.20 \\
$\mathrm{Chromium}$ & Headache, diarrhea, nausea, vomiting, carcinogenic & 0.05 \\
$\mathrm{Arsenic}$ & Skin manifestations, visceral cancers, vascular disease & 0.050 \\
$\mathrm{Cd}$ & Cd Kidney damage, renal disorder, human carcinogen & 0.01 \\
$\mathrm{~Pb}$ & Damage the fetal brain, diseases of the kidneys, circulatory system, and nervous system & 0.006 \\
$\mathrm{Mercury}$ & Rheumatoid arthritis, and diseases of the kidneys, circulatory system, and nervous system & 0.00003 \\
\hline \hline
\end{tabular}

Nevertheless, these types of resins are only efficient at low concentrations of HMI. After long time use, the resin bed becomes contaminated with higher concentrations of solids in water. Another limitation to apply these resins is their selective and sensitive nature toward any change of $\mathrm{pH}$.

There are many studies that have shown that adsorption techniques are economical and effective for removal of HMI. Therefore, activated carbon (AC) (Joshi, 2017), clay minerals, bio-materials and zeolites (Barakat, 2011) have been widely used adsorbents for adsorption of HMI. However, AC got edge over other adsorbents because of its high surface area and pore size and is considered highly efficient for removal of HMI particularly from industrial waste water (Li et al., 2020; Ahiduzzaman and Islam, 2016). Many natural materials or certain waste produced from industrial or agricultural operations are mostly inexpensive and have high economic value. Such low cost materials include waste bamboo, coconut shell, waste tires, animal bones, bagasse, kernel shells, orange peel and rice husk (Irfan et al., 2020 a; and b; Menya et al., 2018). However out of these, rice husk is least used and richly available in most of the developing countries. It is reported that approximately $20 \%$ weight of paddy rice consists of rice husks that generate 148 million metric tons of rice husk globally per year. Moreover, only $17 \%$ of this massive quantity of waste finds its applications which indicate that a very large amount of rice husks turns into waste (Menya et al., 2018). In Pakistan, rice is the third largest crop produced after wheat and cotton and is cultivated during the summer season. The average annual rice production in the country is about 7000 metric tons, from which a huge quantity of rice husk is produced up to 2000 metric tons per year (Mirani et al., 2013). Under the current energy and economic scenario of the country, it is not affordable to waste this massive quantity of biomass. Therefore, it is a common practice to utilize this biomass at power plant sites for combustion to generate steam and electricity. In addition to this, many alternative ways are anticipated to retrieve more efficient applications to make full use of this biomass. Therefore, in recent years, rice husk has been employed as precursor to produce zeolite, silica, concrete and AC (Le Van and Thi, 2014).

Due to huge demand and prolific use, AC remains an expensive material on commercial scale. This factor has always inspired researchers to develop an economical and readily available adsorbent for removal of HMI. Thus, the aim of this present study is to produce low cost adsorbent with high surface area using an agro industrial by-product such as rice husk for its efficient utilization. The synchronization effects of base leaching, addition of activating agent (zinc chloride) and acid washing were also observed on the surface area and other physico-chemical properties of the developed material. The produced material was employed in both non-activated carbon (NAC) and AC forms to investigate its effect on the removal of $\mathrm{HMI}$, including $\mathrm{Ni}, \mathrm{Zn}, \mathrm{Cd}$ and $\mathrm{Pb}$ from water. In addition, an enhancement factor was also established to better evaluate the removal efficiency of HMI using NAC and AC.

\section{Materials and Methods}

Preparation of activated carbon. The characteristics of AC are dependent on the source from which it is being prepared and the type of process used for activation. Rice husk was obtained from a local Rice Mill. The key characteristics of raw rice husk are given in Table 2. Raw rice husk was washed thoroughly with tap water followed by deionized water to remove dust and other contamination. After then, it was oven dried at $110{ }^{\circ} \mathrm{C}$ for $24 \mathrm{~h}$ to eliminate the moisture contents and base leaching was also performed for drying rice husk. For this, rice husk was refluxed using aqueous 
Table 2. Chemical composition of rice husk expressed in $\%$

\begin{tabular}{ll}
\hline \hline Parameters & Value (\%) \\
\hline Total moisture & 5.54 \\
Ash & 15.35 \\
Volatile matter & 63.44 \\
Fixed carbon & 15.67 \\
Composition of ash of rice husk & \\
$\mathrm{SiO}_{2}$ & 93.58 \\
$\mathrm{Al}_{2} \mathrm{O}_{3}$ & 0.478 \\
$\mathrm{Fe}_{2} \mathrm{O}_{3}$ & 0.110 \\
$\mathrm{CaO}$ & 1.016 \\
$\mathrm{MgO}$ & 0.375 \\
$\mathrm{Na}_{2} \mathrm{O}$ & 1.132 \\
$\mathrm{~K}_{2} \mathrm{O}$ & 2.330 \\
$\mathrm{TiO}_{2}$ & 0.012 \\
$\mathrm{SO}_{3}$ & 0.514 \\
$\mathrm{P}_{2} \mathrm{O}_{5}$ & 0.452 \\
$\mathrm{~V}_{2} \mathrm{O}_{3}$ & 0.001 \\
\hline \hline
\end{tabular}

solution of sodium hydroxide $(\mathrm{NaOH}, 1 \mathrm{M})$ at $100^{\circ} \mathrm{C}$ for $24 \mathrm{~h}$. After this, material was filtered and washed thoroughly with distilled water to completely remove the basic contents following by oven drying. Then, the surface of dried material was chemically activated. The key benefit to activate the material is to increase the surface area of formed material to enhance its adsorption capacity. Many activating agents can be used for surface activation, however, activation through zinc chloride produces higher mass loss and rapid rate of thermal decomposition (Li et al., 2020). In addition, activation with $\mathrm{ZnCl}_{2}$ also required low temperature and less duration for pyrolysis of rice husk to achieve swift activation reaction. Therefore, dried material achieved from the oven was chemically activated by immersing it into $10 \% \mathrm{ZnCl}_{2}$ solution for $24 \mathrm{~h}$ with continuous stirring at $100 \mathrm{rpm}$. It was then subjected to heat treatment and pyrolyzed at $450{ }^{\circ} \mathrm{C}$ for destructive carbonization providing mean residence time up to $4 \mathrm{~h}$ in a small sealed steel container (Rahman et al., 2012). Heated crucible was carefully taken out and placed in a desiccator for steady cooling to achieve ambient temperature. Prepared material was grounded into fine powder form. and treated with HCL 1M and extensively washed with deionized water to remove ash contents and residual chemicals. Charcoal was again placed in an oven to dry the prepared material at $110{ }^{\circ} \mathrm{C}$ followed by cooling and preserved in an airtight jar to further use in experimental study. Same methodology was adopted to prepare NAC as was used to prepare AC except to base leaching and chemical treatment processes.
The values of $\mathrm{C}, \mathrm{H}, \mathrm{N}$ and $\mathrm{S}$ of the material were determined through Vario Macro Elementar CHNOS Analyzer (S.N: 11046079). The volatile matter, ash, moisture contents and surface area were measured by using standard methods reference number ASTM E 897- 88 R04, E 830-87 R04, E 949 - 88 R04 and iodine adsorption number ASTM D 1050 - 1 respectively.

Preparation of HMI stock solution. Water stock solutions of $\mathrm{HMI}$ including $\mathrm{Ni}, \mathrm{Zn}, \mathrm{Cd}$ and $\mathrm{Pb}$ were prepared in a laboratory with concentration of 1000 ppm. These stock solutions were further diluted to 2 , $4,6,8,10,20,30,50,100,150$ and 200 ppm solutions for each HMI.

Batch adsorption tests on NAC and AC. The batch process was employed for experimentations to avoid any adjustment of volume correction. Each sample was subjected to a batch adsorption test using NAC and AC for a batch time of $80 \mathrm{~min}$. During experimentations, solution was continuously stirred with constant agitation speed to enhance the rate of mass transfer along with high interfacial area of contact. The initial and final concentrations of HMI after completion of experiment were determined through PerkinElmer Analyst-400 Atomic Absorption Spectrometer after filtering the adsorbent from solution.

For analysis, $100 \mathrm{~mL}$ of each sample was taken and investigated for following effects;

- $\quad$ First, the effects of different concentrations of HMI were studied using constant doses of AC and NAC. It was investigated by using the HMI samples of different concentrations including 2 , $4,6,8,10,20,30,50,100,150$ and $200 \mathrm{ppm}$ of $\mathrm{Ni}, \mathrm{Zn}, \mathrm{Cd}$ and $\mathrm{Pb}$ and using $0.5 \mathrm{~g}$ of $\mathrm{NAC}$ and $\mathrm{AC}$ in a batch process.

- Secondly, the effects of various doses of AC and NAC were studied for HMI removal by keeping constant concentration of HMI. To perform, 50 ppm solution of HMI was treated with various quantities of adsorbent starting from $0.1 \mathrm{~g}$. Dose of each adsorbent was gradually increased till the percentage removal of HMI became almost constant. Each sample was analyzed separately with precautionary measures.

Enhancement factor $(\alpha)$. Enhancement factor $(\alpha)$ was evaluated by dividing the percentage removal of HMI using NAC to the percentage removal of HMI using AC mathematically, 
$\alpha=\frac{\% \text { age removal of HMI using NAC }}{\% \text { age removal of HMI using AC }}$

\section{Results and Discussion}

Characterization of activated and non activated carbon. The physico-chemical characteristics of NAC and $\mathrm{AC}$ are presented in Table 3. It illustrates 51.15 and $77.76 \%$ of $\mathrm{C}$ in NAC and derived AC. The percentages of other elements including hydrogen, oxygen, sulfur and ash are measured as $0.66,34.91,0.19$ and $12.86 \%$ and $0.43,17.32,0.10$ and $4.21 \%$ in NAC and $\mathrm{AC}$ respectively. In addition, the surface area of $\mathrm{AC}$ was measured as $1840 \mathrm{~m}^{2} / \mathrm{g}$ that is quite high when compared with NAC. These results are in accordance with previous study (Menya et al., 2018; Liou and Wu, 2009). Elemental analysis of rice husk before and after its activation exhibits many changes in percentage of carbon, hydrogen and oxygen. Results showed significant changes in carbon and its percentage was increased from $51.15 \%$ measured in NAC to $77.76 \%$ in activated material. However, an opposite trend was observed in percentages of hydrogen and oxygen. Reduction in these elements could be due to combustion of material that resulted in the formation of carbon dioxide, water and organic acids including acetic acid and formic acid (Liou and $\mathrm{Wu}, 2009$ ). In addition, the percentage of ash contents was also decreased that recognized the reaction of silica with active agent like $\mathrm{ZnCl}_{2}$ which resulted in achieving high carbonaceous material along with low ash contents. The selectivity of $\mathrm{ZnCl}_{2}$ as an activating agent was made due to its enhanced ability to make the surface of the material more active. Therefore, the surface area of $\mathrm{AC}$ achieved through chemical activation by $\mathrm{ZnCl}_{2}$ was found significantly higher in comparison with NAC that was prepared without any chemical activation. In fact, addition of activating salt enhances the contact area between raw rice husk and activating agent that results

Table 3. Physio-chemical characteristics of NAC and $\mathrm{AC}$ expressed in \%

\begin{tabular}{lll}
\hline \hline Parameters & NAC & AC \\
\hline Ash (\%) & 12.860 & 4.210 \\
Surface area $\left(\mathrm{m}^{2} / \mathrm{g}\right)$ & 334 & 1840 \\
Carbon $(\%)$ & 51.154 & 77.760 \\
Hydrogen (\%) & 0.662 & 0.439 \\
Nitrogen (\%) & 0.212 & 0.162 \\
Sulfur (\%) & 0.192 & 0.103 \\
Oxygen (\%) & 34.918 & 17.324 \\
\hline \hline
\end{tabular}

in an increase of surface area of AC. In addition, after completion of the activation process, zinc salts can be easily removed due to their higher solubility in water. This phenomenon also yields more developed pores which are favourable to achieve enhanced absorption capacity of developed material. Similar observation was reported out by Chen et al. (2017) that used different activating agents including $\mathrm{KOH}, \mathrm{K}_{2} \mathrm{CO}_{3}$ and zinc chloride with different impregnation ratios and last one was found more efficient activating agent to enhance the surface area of material. Furthermore, the reduction of ash contents from 12.86 to $4.21 \%$ also revealed the disappearance of silica providing new pores structure and ultimately result in achieving high surface area. The inverse relation between the percentages of ash content and surface area of activated carbon is in accordance with the past studies (Maulina and Iriansyah, 2018). It means that any reduction of ash contents could be an index of increase of surface area and vice versa.

Effect of metal ions concentration. Initial concentration of adsorbate is considered as one of the active parameters to access the adsorption efficiency of any adsorbent material. Therefore, effect of various concentrations of HMI was investigated using fixed amount of adsorbents i.e. NAC and AC. The experimental results to identify the effect of initial metals concentration ranging from 2 - 200 ppm are illustrated in Fig. 1. It was observed that increasing the concentrations of HMI resulted in less percentage removal of HMI from solution. Results showed that percentage removal of HMI was approximately measured as 69, 64, 62 and $56 \%$ for $\mathrm{Ni}$, $\mathrm{Cd}, \mathrm{Zn}$ and $\mathrm{Pb}$ respectively when $2 \mathrm{ppm}$ of $\mathrm{HMI}$ water sample was treated with NAC. On increasing concentration of HMI up to $200 \mathrm{ppm}$, percentage removal of HMI was reduced and measured as 46, 40, 36 and 29\% for $\mathrm{Ni}, \mathrm{Cd}, \mathrm{Zn}$ and $\mathrm{Pb}$ respectively as illustrated in Fig. 1. These results revealed that removal efficiency of HMI is highly dependent on initial concentration of HMI present in the solution. It is a fact that when concentration of HMI increases by keeping the adsorbent quantity constant, metal ions have lesser surface area available per unit for adsorption (Padmavathy et al., 2016). In case of less concentrations of $\mathrm{Ni}, \mathrm{Cd}, \mathrm{Zn}$ and $\mathrm{Pb}$ in the solution, the ratio for initial number of moles of metals ions per volume is small. Therefore, probability for metals ions to get adsorbed per available surface area of adsorbent is quite high that exhibited as an effective removal of metals ions. On the contrary, higher concentrations of HMI provided more number of moles 


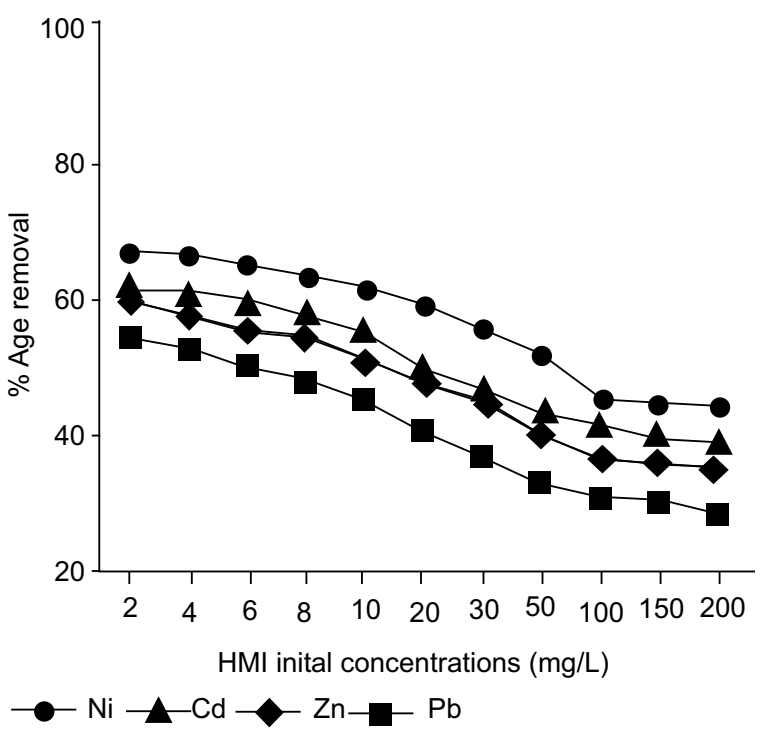

Fig. 1. Atomic absorption spectrometer analysis: an investigation to identify the effect of initial concentration of metal ions present in the sample on rate of adsorption using $\mathrm{NAC}$ as an adsorbent material.

of ions per unit area of adsorbent that resulted in less efficacy of material with low percent recovery of metals ions from solution.

This phenomenon was further endorsed when $\mathrm{AC}$ was employed for adsorption of HMI, where the surface area of prepared material was relatively high. In this case, the maximum percentage removal of HMI was measured as 99.0, 95.5, 93.0 and $89 \%$ for $\mathrm{Ni}, \mathrm{Cd}, \mathrm{Zn}$ and $\mathrm{Pb}$ respectively using $2 \mathrm{ppm}$ of initial concentration of metals in solution. It shows that percent removals of HMI were elevated upto $30,31.5,31$ and $33 \%$ for $\mathrm{Ni}$, $\mathrm{Cd}, \mathrm{Zn}$ and $\mathrm{Pb}$ respectively ratifying the efficiency of the AC in comparison with NAC. However, again it was observed to decrease the removal efficiency of HMI when initial concentration of HMI was increased up to $200 \mathrm{ppm}$. Using initial concentration of HMI as $200 \mathrm{ppm}$, percentage removal was observed relatively less and measured as 82, 68, 61 and 51 for $\mathrm{Ni}, \mathrm{Cd}, \mathrm{Zn}$ and $\mathrm{Pb}$ respectively as shown in Fig. 2. Even though, the trends for removal of HMI were quite similar using both NAC and AC. However, later one was observed substantially more efficient. AC is effective for HMI removal because of its more porous structure and high surface area (Sweetman et al., 2017). Consequently, it provides a large number of binding sites to adsorbent

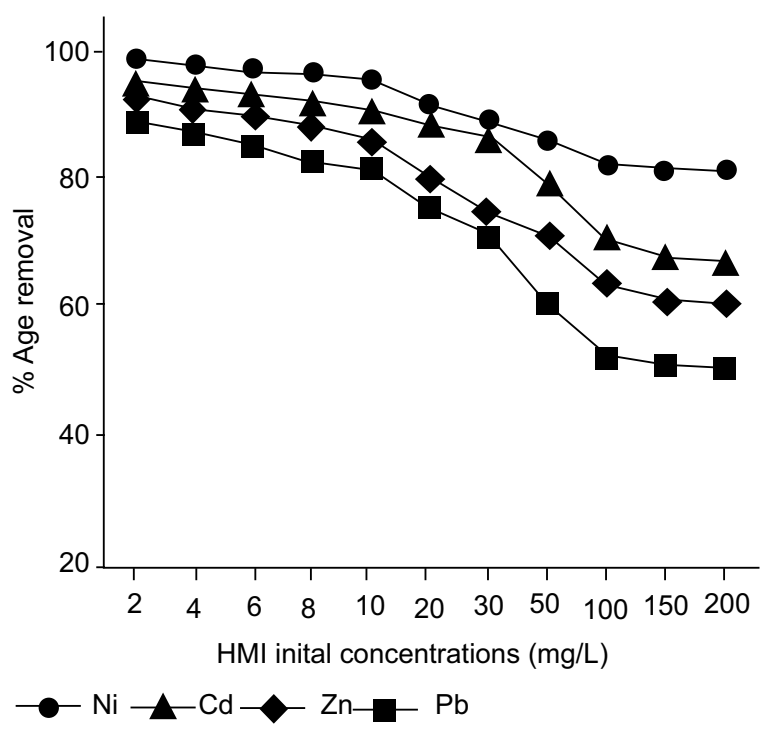

Fig. 2. Atomic absorption spectrometer analysis: an investigation to identify the effect of initial concentration of metal ions present in the sample on rate of adsorption using $\mathrm{AC}$ as an adsorbent material; activation of material raised the adsorption curves to reflect the enhanced rate of adsorption.

species for interactions which resulted in higher removal of metals ions from solution.

Overall comparison of enhancement factor $(\alpha)$ for the effect of metal ion concentration on adsorption is shown in Fig. 3. Enhancement factor $(\alpha)$ was little bit higher when the concentration of metal ions was low into solutions. However, its value was gradually decreased with an increase of concentration of metal ions. In fact, using higher concentration of HMI, binding sites of adsorbent were rapidly saturated which lead toward reduction in equilibrium period. On contrary, less concentration of HMI in solution provided more contact time and space to get adsorbed the heavy metals on the surface of adsorbent which resulted in more removal efficiency and higher value of enhancement factor.

Effect of adsorbent quantity on adsorption. The effect of NAC and AC doses was studied by keeping constant concentration of metal ions in solution. Initial dose of adsorbents was kept at $0.1 \mathrm{~g}$ and continuously increased for removal of each metal until a constant value for percent removal of HMI was achieved. The effect of increase of adsorbent doses for removal of HMI by NAC and AC are presented in Fig. 4 and 5. It 


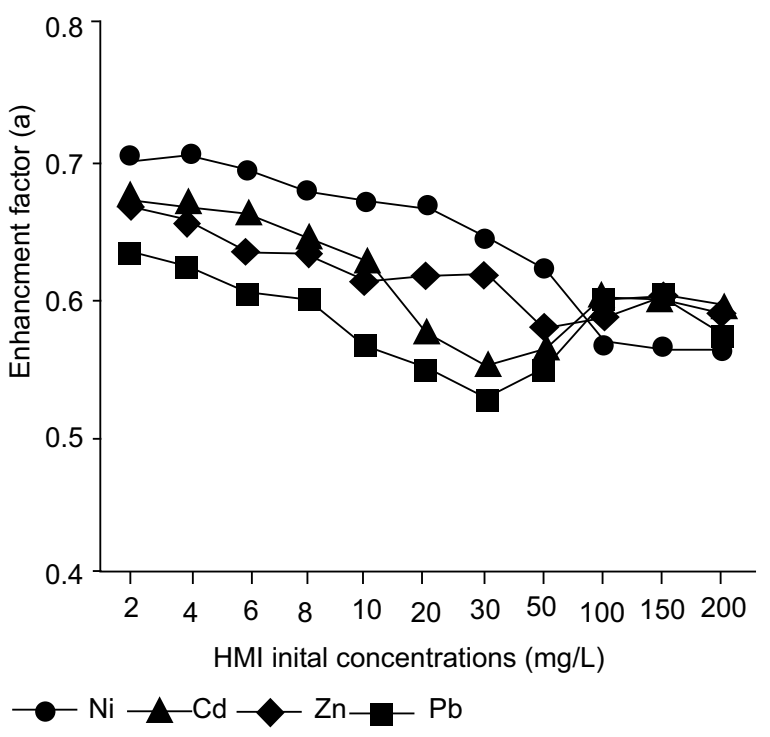

Fig. 3. Variations in enhancement factor $(\alpha)$ to evaluate the effect of initial concentrations of metals on adsorption.

was observed that any increase of dosing rate of NAC and $\mathrm{AC}$ resulted in higher percent removal of $\mathrm{HMI}$ since the contact surface of adsorbent units was increased. In fact, any increase of dosing rate of adsorbent in the solution provided the accessibility of more active sites for enhanced rate of adsorption that improved the penetration of metallic ions toward adsorption sites.

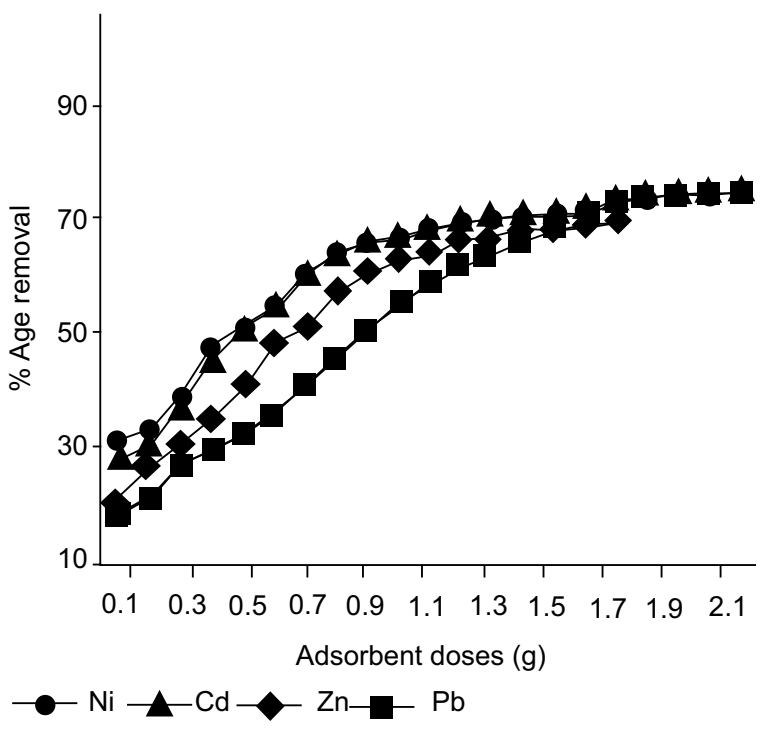

Fig. 4. Atomic absorption spectrometer analysis: graphical array to examine the effect of doses of NAC on \%age removal of HMI.
Results showed that initial percentage removal of $\mathrm{Ni}$ was measured as 31.98 that became almost constant up to $66.61 \%$ using $1.2 \mathrm{~g}$ of adsorbent. Similarly, the percentage removal of $\mathrm{Cd}, \mathrm{Zn}$ and $\mathrm{Pb}$ were increased from $28.91,21.56$ and $19.67 \%$ to $71.08,69.52$ and $73.27 \%$ when adsorbent doses were increased from 0.1 $\mathrm{g}$ to $1.5,1.7$ and $2.1 \mathrm{~g}$ respectively. Similar effect of dosing rate was also investigated using $\mathrm{AC}$ as adsorbent material. Results showed that using $\mathrm{AC}$, percentage removals of HMI were observed relatively higher and measured as 56.0, 52.5, 44.5 and $37.0 \%$ for $\mathrm{Ni}, \mathrm{Cd}, \mathrm{Zn}$ and $\mathrm{Pb}$ respectively while treating $0.1 \mathrm{~g}$ of $\mathrm{AC}$ as shown in Fig. 5. The percent removal of HMI was further elevated to $98.74,93.81,91.74$ and $93.53 \%$ when adsorbent dose was increased 1.2, 1.5, 1.7 and $2.1 \mathrm{~g}$ for $\mathrm{Ni}, \mathrm{Cd}, \mathrm{Zn}$ and $\mathrm{Pb}$ respectively. It shows that any change in percent removal of HMI was minor even any increase of the amount of AC. Therefore, these amounts of AC can be considered as optimum for economical purposes.

The value of enhancement factor $(\alpha)$ also showed a rise with increase in adsorbent doses as demonstrated in Fig. 6. The values of $\alpha$ was observed as $0.57,0.55,0.53$ and 0.47 to $0.70,0.76,0.76$ and 0.80 for $\mathrm{Ni}, \mathrm{Cd}, \mathrm{Zn}$ and $\mathrm{Pb}$ respectively. Any increase of dosing rates may result in higher surface area and availability of more active sites. Furthermore, the higher HMI removals from the solution is also attributed to enriched

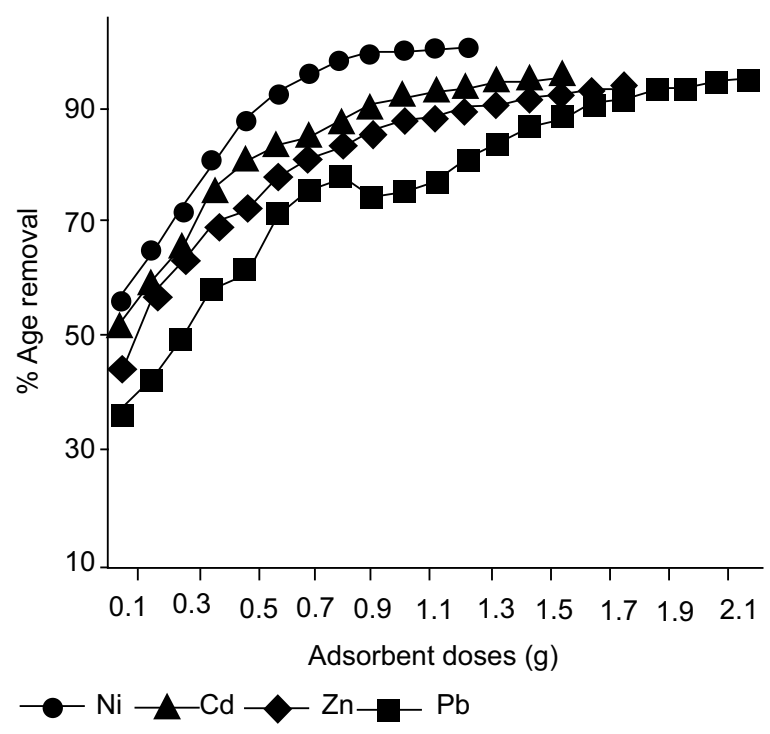

Fig. 5. Atomic absorption spectrometer analysis: graphical array to examine the effect of doses of AC on \%age removal of HMI. 


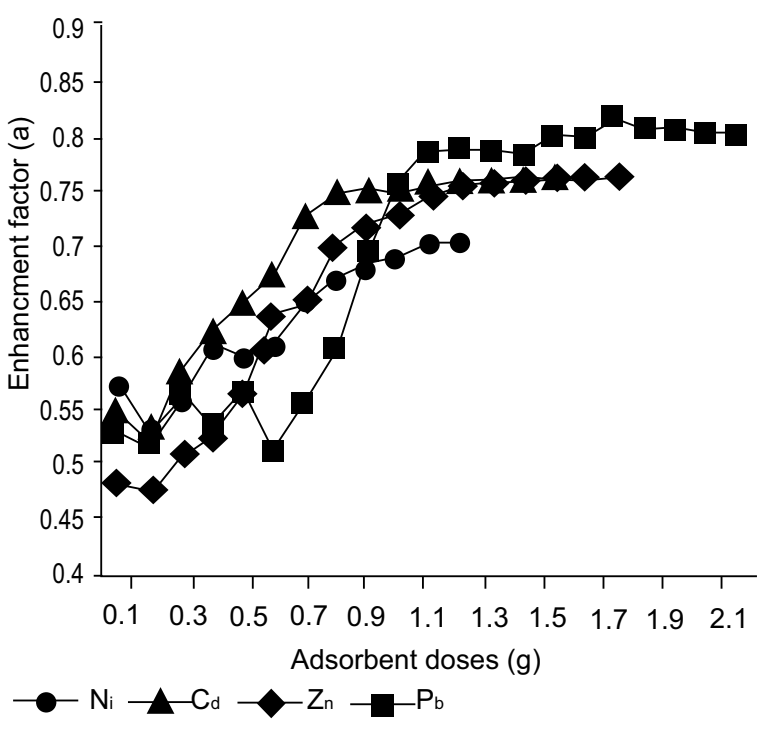

Fig. 6. Variations in enhancement factor $(\alpha)$ to evaluate the effect of adsorbent dose on percentage removal of HMI.

concentration of $\mathrm{AC}$ which resulted in substantial removal of metals ions compared with NAC. Similar results were observed when granular AC used for removal of dyes from solution (Han et al., 2009).

\section{Conclusion}

This study shows the successful preparation of inexpensive, porous and efficient activated carbon using a biomass waste material i.e. rice husk which is easily available in any agrarian country. The developed material was activated by the composite effect of base leaching, addition of $\mathrm{ZnCl}_{2}$ and acid washing which provided a large surface area of material even at low temperatures. The prepared materials have been found to be effective in removing heavy metals from solution with and without any activation. However, the activated material was found to be superior for HMI removal when compared with NAC. The removal efficiency of HMI using AC is found in order of $\mathrm{Ni}>\mathrm{Cd}>\mathrm{Zn}>\mathrm{Pb}$. Hence, the initial concentration of metals and the dose of adsorbent are important factors to optimize the percentage removal of HMI from any effluent. The present study demonstrates an efficient way to transform local biomass into a resourceful material for several industrial applications and this process can be easily scaled up for bulk production.

Conflict of Interest. The authors declare no conflict of interest.

\section{References}

Ahiduzzaman, M., Islam, A. S. 2016. Preparation of porous bio-char and activated carbon from rice husk by leaching ash and chemical activation. Springer Plus, 5: 1248.

Barakat, M. 2011. New trends in removing heavy metals from industrial wastewater. Arabian Journal of Chemistry, 4: 361-377.

Bashir, A., Malik, L. A., Ahad, S., Manzoor, T., Bhat, M. A., Dar, G., Pandith, A. H. 2019. Removal of heavy metal ions from aqueous system by ionexchange and biosorption methods. Environmental Chemistry Letters, 17: 729-754.

Chen, R., Li, L., Liu, Z., Lu, M., Wang, C., Li, H., Ma, W., Wang, S. 2017. Preparation and characterization of activated carbons from tobacco stem by chemical activation. Journal of the Air \& Waste Management Association ,67: 713-724.

Fu, Z., and Xi, S. 2020. The effects of heavy metals on human metabolism. Toxicology Mechanisms and Methods, 30: 167-176.

Han, R., Wang, Y., Zhao, X., Wang, Y., Xie, F., Cheng, J., Tang, M. 2009. Adsorption of methylene blue by phoenix tree leaf powder in a fixed-bed column: experiments and prediction of breakthrough curves. Desalination, 245: 284-297.

Irfan, M., Ahmad, T., Moniruzzaman, M., Bhattacharjee, S., Abdullah, B. 2020a. Size and stability modulation of ionic liquid functionalized gold nanoparticles synthesized using Elaeis guineensis (oil palm) kernel extract. Arabian Journal of Chemistry, 13: 75-85.

Irfan, M., Siddiqui, M., Bashir, F., Butt, M., Abbas, N. 2020b. Efficient removal of hydrogen sulfide from wastewater using waste-tire-derived rubber particles. International Journal of Environmental Science and Technology, 17: 3515-3524.

Joshi, N.C. 2017. Heavy metals, conventional methods for heavy metal removal, biosorption and the development of low cost adsorbent. European Journal of Pharmscy Medical Research, 4: 388393.

Le Van, K., Thi, T.T.L. 2014. Activated carbon derived from rice husk by $\mathrm{NaOH}$ activation and its application in supercapacitor. Progress in Natural Science: Materials International, 24: 191-198. Li, Y., Li, Y., Zang, H., Chen, L., Meng, Z., Li, H., Ci, L., Du, Q., Wang, D., Wang, C. 2020. $\mathrm{ZnCl}_{2}$ - 
activated carbon from soybean dregs as a high efficiency adsorbent for cationic dye removal: isotherm, kinetic, and thermodynamic studies. Environmental Technology, 41: 2013-2023.

Liou, T.-H., Wu, S.-J. 2009. Characteristics of microporous/mesoporous carbons prepared from rice husk under base-and acid-treated conditions. Journal of Hazardous Materials, 171: 693-703.

Malik, L.A., Bashir, A., Qureashi, A., Pandith, A.H. 2019. Detection and removal of heavy metal ions: a review. Environmental Chemistry Letters, 1-27.

Masindi, V., Muedi, K.L. 2018. Environmental contamination by heavy metals. Heavy Metals, 19: 2019. DOI: 10.5772/intechopen. 76082.

Maulina, S., Iriansyah, M. 2018. Characteristics of activated carbon resulted from pyrolysis of the oil palm fronds powder. In "IOP Conference Series: Materials Science and Engineering", Vol. 309, pp. 012072. IOP Publishing.

Menya, E., Olupot, P., Storz, H., Lubwama, M., Kiros, Y. 2018. Production and performance of activated carbon from rice husks for removal of natural organic matter from water: a review. Chemical Engineering Research and Design, 129: 271-296. Mirani, A.A., Ahmad, M., Kalwar, S.A., Ahmad, T. 2013. A rice husk gasifier for paddy drying. Science and Technology Development, 32: 120-125.

Padmavathy, K., Madhu, G., Haseena, P. 2016. A study on effects of $\mathrm{pH}$, adsorbent dosage, time, initial concentration and adsorption isotherm study for the removal of hexavalent chromium (Cr (VI)) from wastewater by magnetite nanoparticles. Procedia Technology, 24: 585-594.

Rahman, M.A., Amin, S.R., Alam, A.S. 2012. Removal of methylene blue from waste water using activated carbon prepared from rice husk. Dhaka University Journal of Science, 60: 185-189.

Sweetman, M.J., May, S., Mebberson, N., Pendleton, P., Vasilev, K., Plush, S.E., Hayball, J. 2017. Activated carbon, carbon nanotubes and graphene: Materials and composites for advanced water purification. Journal of Carbon Research, 3: 18. 